\title{
Subdural Hematoma
}

National Cancer Institute

\section{Source}

National Cancer Institute. Subdural Hematoma. NCI Thesaurus. Code C116585.

A collection of blood between the dura mater and the brain. 